\title{
Theorising the value of collage in exploring educational leadership
} (revised version, submitted 27th April 2018)

\author{
Authors: Dr Amanda Roberts and Professor Philip A. Woods \\ E-mail addresses: a.roberts2@herts.ac.uk (for correspondence); p.a.woods@hert- \\ $\underline{\text { s.ac.uk }}$
}

Twitter username: @PhilipWoodsProf

Postal address: School of Education, University of Hertfordshire, College Lane, Hatfield, AL10 9AB, UK

\begin{abstract}
This article contributes to theorising the value of collage as a methodological approach. It begins with a discussion of the methodological difficulties of exploring hidden meanings and individual experience through the research process. The illuminative potential of arts-based methodologies in qualitative research is then investigated. The article makes the case for the specific advantages of using collage to explore the experience of leadership, through a discussion of two collage-based studies. It proposes a variant of the 'think aloud' process, used in conjunction with collage, as a route to producing deep understandings of the multiple ways in which leadership is experienced and understood as a social process. The argument is made that collage enables the accessing and sharing of profound levels of experience not accessible through words alone and considers the impact of the physicality of collage on its potential to release these profound insights. A five stage process for the analysis of collage is then set out. The article concludes by offering a theory of the value of collage as a methodological approach to exploring experiences of leadership, through use of the concepts of physicality, wholeness and participant agency.
\end{abstract}

\section{Introduction}

In this article we seek to address a methodological problem which we have grappled with in our leadership research, namely, 'how can we uncover understandings of leadership by social actors which are not brought to the surface by conventional research methods such as interviews?'. Such understandings may be termed 'unconscious'. In this context we use the term 'unconscious' to mean those understandings about leadership and the experience of leadership which lie below conscious thought and reasoning. We turned to arts-based approaches and, in particular, collage, to help us to solve this methodological difficulty. In this article we explore our experience of using collage as a methodological approach in two research studies. We offer a five point process for the analysis of the collages produced and explore the meaning of the physicality of the collage-making process. We conclude by offering a theory of the value of collage as a 
methodological approach to exploring experiences of leadership, through the use of the concepts of physicality, wholeness and participant agency.

\section{The appeal of arts-based research approaches}

In human experience, there are points where words are inadequate to explain what is known, felt or believed (Frosh, 2002, cited in Leitch, 2006). In professional practice, such a proposition is further illuminated by the concept of tacit knowledge (Polyani, 1967, cited in Eisner, 2004) - 'people know more than they can tell' (Sternberg and Horvath, 2009:ix). It is often difficult to express the most profound knowings in propositional form. Such profound knowings differ from the everyday understanding of professional practice which relate to systems and practices which can be relatively easily explained, quantified and passed on. An example of such practices might be the way in which attendance at work is monitored and the sanctions which are applied when the stated rules are breached. We are talking instead about the lived experience of leadership, how it feels to lead or be the subject of leadership. Arts-based research offers participants an alternative way of representing such profound feelings, responses and understandings.

There is a body of literature that demonstrates the opportunity images open up for research participants to explore the subtleties of experience in creative, non-linear ways (Loads, 2009; Spouse, 2000; Leitch, 2006; Black, 2002). In terms of leadership, we hoped that this non-linearity would allow participants to make meaning across the range of their leadership experiences, making connections between one set of experiences and another, linking thoughts and feelings to produce a nuanced picture of how they see the leadership practice. Such potential for non-linearity contrasts with that offered by the invitation to answer a posed question with a linked train of thought encouraged by more conventional methods such as structured interviews.

We have argued elsewhere (Woods and Roberts, 2018) that acknowledging the relevance of complexity theory (Stacey, 2012) to leadership research allows a deep analysis of the myriad of ongoing interactions which characterise organisational leadership. Complexity theory suggests leadership is not reducible to the learning of certain techniques, procedures and generalisations about effective leading. Instead, the capabilities required are both more demanding and ambitious and, Stacey suggests, are needed to deal with the uncertainty and ambiguity which characterise leadership. Such skills call for sensitive awareness and intuition (Stacey, 2012). It is this complexity which artsbased approaches allow participants to reflect upon and express, slowing down and honouring the meaning-making (Loads, 2009) and validity of their unique experiences of their own and others' leadership.

In contrast to some other data collection methods such as interviews, within arts-based research the pace of the response to the researcher's stimulus is dictated by the participant, who makes the collage in their own time and has the facility to reflect, move pieces and re-arrange their response as their thinking develops. Respect is offered to 
such a process through both the giving of time and the acceptance of whatever is offered as valid and illuminative. Eisner's (1993) proposition that art is not simply an alternative way of representing knowledge, but allows the release of different forms of understanding, renders it relevant as a methodological approach for researching leadership activity. It was such unconscious aspects of the experience of leadership which we sought to enable our research participants to reveal. As we began to indicate in the introduction, 'unconscious' for us means the experiences of leadership which are most deeply felt and which include experiences, memories, thought-processes and motivations which have not been consciously reflected upon and understood.

The status of arts-based research has been challenged by concerns over its validity for such knowledge creation. We concede that seeking knowledge about leadership based on claims of certainty would find little use for arts-based research. However, our understanding of the experience of leadership as socially constructed gives clear validity to such an approach. Moreover, our quest to deepen our understanding of a variety of stakeholders' experiences of distributed leadership positively recommends it. In our research then, the validity of an arts-based approach arose from its capacity to give an insight into the particular experiences of individuals. It is through the faithful presentation of their multiple perspectives that validity arises. Arts-based methods enable the variety and complexity of participants' experiences to be expressed, recognising that these experiences are valid for them. At the same time, drawing on Simons (2009), we also sought to secure some degree of generalisability through the surfacing of recognisable insights, that is, insights that others would perceive as in some ways apparent in practice in their own settings, albeit located in the particularity of individual experiences.

\section{Collage within the arts-based research field}

By collage we mean the placing, rather than sticking, of representational and non-representational objects such as pictures, paper, man-made and natural materials, onto a large sheet of paper in order to make meaning, in this case, meaning around the understanding of leadership. Butler-Kisber and Poldma (2010:3) identify three uses of collage in qualitative research: 'as a reflective process, as a form of elicitation, and as a way of conceptualising ideas'. We now explore how each of these functions accorded with our particular purposes.

Collage's capacity to act as a reflective process recommended it to us above other artsbased approaches. We were interested in stimulating our research participants to consider deeply their particular experience of leadership. The creation of metaphors for feelings and experiences necessitated by the collage-making process allows for more imaginative and reflective connection-making than words might allow (James \& Brookfield, 2014). The slowing down of meaning-making occasioned through the linked collage processes of choosing materials to represent something, considering where such materials should be placed and why and the viewing of the completed whole, had the capacity to support the deep reflection we were seeking. 
Collage's potential to support elicitation, the bringing forth of different forms of understanding, links with its reflective potential. The efficacy of images in uncovering hidden or unconscious aspects of experience (Weber \& Mitchell, 1996; Thaiss \& Zawacki, 2006) recommended it to us, according with our interest in the totality of participants' experience and understandings of leadership. Collage, in comparison with arts-based approaches such as photography, appears to allow for a deeper engagement with these unconscious experiences of leadership. In Luttrell's (2010) participatory, image-making research with children, for example, choices of photograph to take and the consequent explanations of them appear to have had a conscious, understood purpose. We suggest that collage as a research approach allows for the creation of a new, more profound kind of knowledge through an exploration of that which has not previously been either known or acknowledged. As such, the term 'unconscious' denotes something deeper than 'unexpressed'. Such a proposal is supported by the reaction of participants to artsbased approaches across the breadth of our work in this field, where participants commonly share their surprise at what they have created.

We were particularly interested in the capacity of collage to act as a means to conceptualise ideas. Collage would allow our research participants to represent people, organisations, events, feelings, reactions and so on through tangible objects which could then be moved around, grouped, themed and so on. This sense-making activity appeared to allow for the expression of tentative and then revised understandings of leadership as pieces are placed then moved and moved again until either a new way of expressing original thoughts or a new way of seeing existing ideas has been achieved (Gauntlett, 2011; Butler-Kisber \& Poldma, 2010). Images produced through collaging also give the possibility of creating a picture of experience in which the meaning of objects is defined by their relationship to another, through visual juxtapositioning (Butler-Kisber, 2008), rather than through an intrinsic individual quality (Robertson, 2002, in Butler-Kisber and Poldma, 2010). Such juxtaposing seemed particularly relevant to making meaning of the potentially complex understandings of leadership.

Having considered these three functions, collage, within the wider sphere of arts-based research, seemed particularly suited to our purposes. We hoped the process of reflection stimulated by the demands of making a collage would encourage participants to surface and represent their feelings about leadership, as well as their understanding of leadership structures and activity.

Given our interest in power (Woods 2016, in press 2018, Woods and Roberts, 2018) we were particularly aware of the need to break down potential role-based status and authority barriers within our participant groups. We saw ourselves working to an emancipatory agenda, with the research process itself offering participants a degree of agency in what was revealed. Here we use agency to mean human beings' ability to act with some degree of independence, with their actions self-authored rather than wholly determined by others. Arts-based research approaches lend themselves to being conducted collaboratively, having the capacity to break down barriers between researcher and researched (Clandinin et al., 2009; Gourlay, 2009). Indeed, Gale and Wyatt (2006) 
point to the emancipatory nature of the conflation of researcher and researched in such approaches. We therefore designed dialogue between ourselves and participants around the collage into the research process.

The collages were used to open up a dialogue amongst diverse individuals (Diaz, 2002) and to break down the potential for social injustices and inequalities embedded in the status quo (Bagley and Castro-Salazar, 2012). This approach allowed an extended range of voices, including the otherwise marginalised (Gerstenblatt, 2013), to contribute to our understanding of leadership. We were aware of the potential for social desirability bias in this approach, where participants' authentic responses are limited by a consideration of what response will be more acceptable to the group (Holgraves, 2004) or cause the participant least embarrassment (Kaminska and Foulsham, 2013). However, experience of using collage in previous work demonstrated collage's ability to stimulate playfulness and laughter (Roberts, 2016). It was this relaxed approach to data production which we hoped would bring about authentic reflection on experiences of leadership. By authentic reflection we mean a genuine consideration of how to represent the distinct experience (Van Manen, 1990) of leadership from an individual perspective, in contrast to reflection designed to find ways to replicate the accepted view or the perspective imagined to be desired by the researcher or other participants.

\section{Two studies}

We were interested in exploring how a range of individuals experienced leadership in their educational settings. Data was collected as part of two studies ${ }^{1}$. In the first study, data was collected from 29 participants from 1 secondary school: 6 teaching staff; 4 non-teaching staff, 4 senior leaders and 15 students (aged between 11 and 19). The data was gathered over two consecutive days at the school (Woods and Roberts, 2013).

In the second study, participants were drawn from a teacher-led development work (TLDW) group, which was part of the HertsCam Network (see Frost, 2013). The group consisted of 14 professionals in early years education: early years practitioners (4), early years teachers (2), primary school teachers (2), nursery school teachers (4), preschool leader (1) and teaching assistant (1) (Woods et al, 2016), with a range of educational settings therefore represented.

\section{Data gathering process}

\footnotetext{
1 The studies were part of projects funded by the European Commission: the European Policy Network on School Leadership (EPNoSL) (2011-2015) and the European Methodological Framework for Facilitating Teachers' Collaborative Learning (EFFeCT) project (http://oktataskepzes.tka.hu/en/effect-project). Views in this article are those of the authors, and the Commission cannot be held responsible for any use which may be made of the information contained therein.
} 
In both studies, participants worked in peer groups of between 4 and 6 . They were provided with a range of collage-making materials. These included coloured beads, ribbon, sequins, balloons, drinking straws, tissue paper, cellophane, wooden discs, metal nuts and springs, geometrical shapes, animal shapes and feathers. They were asked to make a choice from these materials and place their chosen objects onto a large sheet of paper, in whatever configuration they felt appropriate in order to make a collage in response to the question, 'How would you represent leadership in your school/setting?'.

The direction to 'place' rather than to 'stick' chosen objects was significant. We hoped in this way to allow participants the potential to move objects as their thinking progressed, to shift from an original, tentative idea to one more fully formed in the course of the collage-making process.

Participants were not asked to attempt to produce a comprehensive 'picture' of organisational leadership but to highlight the aspect or aspects of leadership important in their minds and feelings as they created their collage. Participants were then asked to explain their collage to the rest of their group after which group members were invited to pose questions or to make comments. The process of making the collages and the resulting explanation were both audio and video recorded in study 1, and audio-recorded only in study 2 due to technical constraints, to support the analytical process.

It is worth pausing here to consider the possible impacts of asking participants to explain their completed collage in words. This activity could invite a post-hoc rationalisation of the created image which does not accord with its original meaning. We could have avoided this potential challenge to our approach by following Boren and Ramsey's (2000) use of the 'think aloud' technique, that is, asking a person to verbalise their thinking whilst performing a task. However, we found Stratman and Hamp-Lyons' (1994, in Branch, 2001) critique of such verbal protocols convincing. We did not wish to add to the perceived difficulty of the collage-creation task by asking participants to verbalise their thinking at the same time. We therefore employed a variant to this technique, asking participants to explain their collage after its completion. Simultaneous explanations would also have been impossible to capture in a group situation and would therefore have necessitated participants making their collage alone. The potential for group lightheartedness or for discussion or simply quiet support through mutual activity would therefore have been removed.

Another issue is raised by our belief in collage's potential to reveal deep-seated understandings not easily conveyed in words. This might suggest that participants should not be asked to explain their collages at all but that we as researchers should make what sense we can of the images produced. The potential for misreading led us to decide to facilitate and then use participants' own explanation of their collage in the analytical process. However, we remained committed to also using the collages produced as more than the usual secondary illustrations of text (Prosser, 1998). We similarly did not see them as only 'tin-openers' for talk (MacBeath, 2002). Instead, we attempted to attend to the images as images, as conveyors of meaning in their own right. 


\section{The data analysis process}

We combined two analysis approaches to the data gathered in this study, namely empathetic understanding and structured analytical processes. Empathetic understanding involved creative reflection on the data to support our affective insights and non-cognitive awareness of participants' experiences of leadership. We discussed, for example, the feelings evoked in us by the various collages. The structured analytical processes involved methodical procedures to identify patterns and to break the data up, allowing us to label, collate and compare images and their meaning. These analytical approaches were not drawn upon in a wholly structured, linear fashion, with one given priority over the other. Instead they were called upon as appropriate in a holistic approach to understanding the data. We draw upon a combination of both approaches here in offering a five point process for collage analysis.

This process has been derived from our reflections on the analytical activities undertaken across these two studies. It is a summary of important aspects of the analytic process we undertook as researchers.

\section{Listening to the accounts of the collage given by the collage-maker} This was our first step, providing an initial understanding of each participant's story. It supports the validity of any sense-making across collages.

\section{Working as a research team to 'read across' the collages visually}

This was in our case facilitated by spreading the collages out randomly and reflecting together on what struck each of us in the team. In this way the research team can begin to open itself to impressions from the visual creations of participants and perhaps evoke ideas of what the collages are collectively representing (Butler-Kisber, 2008). It allows for the attending to images as images, rather than concentrating only on explanations given through the medium of words.

\section{Grouping the collages according to 'striking elements'}

This stage of the process involved beginning to group the collages in order to see what patterns, if any, presented themselves. The concept of 'striking elements' refers to the features of the collages which stand out for one or more of the researchers. This inductive approach helps us in progressing the analysis towards honouring of the aspects of the participants' stories which appear most significant. The groupings and the reasons for them were then discussed by the research team. Such a dialogic approach to making meaning is not much discussed in the literature. However, the positive nature of participant response to our feeding back of cross-collage interpretations leads to our support for Bresler's (2006) argument that it is a legitimate way of gaining understanding of artistic forms.

\section{Multi-media analysing of the story of the collage}


At this stage, the visual image of each collage was complemented by data in other media which supported its interpretation. Using a template, the research team constructed a commentary on each collage and its associated explanation. This stage of analysis can involve, as appropriate and for each collage, viewing the video of its production, listening to the audio tape, selecting illustrative quotations from the participant's explanation of their collage and making researcher notes on possible concepts and themes which helped us to begin the process of interpretation.

\section{Identifying areas of learning about the topic of leadership}

We came to see certain aspects of leadership and how it is seen as being illuminated by the analytical activities (1 to 4) described above. This fifth activity is an interpretative process where the aim is to be faithful to how participants view leadership and how they describe it through an image (the collage) which is constructed as a completed whole. We explain in the next section key areas of learning about the topic of leadership that emerged from the analytical activities in our two studies.

\section{Learning about leadership}

The full findings from our analytical activities are not presented here as this is not the focus of this article. Instead, particular areas of learning about leadership are offered with the aim of highlighting the fascinating and particular 'window into people's beliefs and experiences' (Bell, 2002: 209) which we believe collage afforded us. These areas of learning are: hierarchy, holarchy, identity and leadership as a social process.

\section{Images of hierarchy}

Examples of images are presented below in the conceptual groupings which arose from our analysis of the collages. The first such grouping is images which represent hierarchy (Figure 1). Although not dominating the collages, such images were strongly represented.

\section{FIGURE 1 HERE}

Hierarchical images were often presented in a triangular shape. The three collages show an image of hierarchy that would likely be understood as such by most people. The creator of the left-hand collage (Figure 1) described the image as 'a pyramid of power' (B3). Power emanates from the top of the pyramid, marked by an image representing the headteacher, and slowly diminishes from this point down. The multi-media analysing (point 3 of the 5-point process above) was helpful in exploring the images further. A more nuanced view of what hierarchical leadership meant to participants is apparent when they explained their collages. Participants expressed differing views on 
the unequal distribution of power. Some expressed contentment with such structures, seeing them as efficient. Others saw inequality in how people are valued as leading to ineffective working. Some participants recognised the attempts being made by those in power to address such issues.

The only reason my headteacher sent me here [to the Teacher-Led Development Work group where the research was taking place] is because they say they value their TAs [Teaching Assistants] and they no longer want to see them at the bottom. They want us to become leaders and to use initiative and to drive things forward ourselves (P5).

Further insights into the ways in which the collage-creators expressed their experiences and views of leadership are given as we discuss the other areas of learning in turn.

Images of holarchy

Holarchic images also featured strongly in the collages. By holarchic images we mean images which constitute a more rounded appearance or give the impression of a network, rather than a hierarchy (Woods and Roberts, 2013).

\section{FIGURE 2 HERE}

In these collages, leadership is seen as distributed throughout the school in a more organic manner, rather than wholly exercised through the power afforded by positional roles. The shape of holarchic images tends to be more circular and fluid than images which present a hierarchical view, yet many have an internal structure which affords a depth of coherence from within.

The creator of the left-hand collage in Figure 2 talked of a spiral which moved from the outside community inwards through the students and then to the teachers. Difference is valued in this holarchical view of leadership. In the central collage, the majority of staff and students are clustered tightly together, illustrating their joint exercise of leadership, although to different degrees, across the school.

The creator of the collage on the right (Figure 2) imagines distributed leadership as the result of an almost spiritual convergence of ideas:

They throw their ideas into the magical wind which moves up through this adventurous path and it gets here to me who mixes it all up and then has an explosion of an idea here and then it comes back down through my body here and it is whipped up into a circle, a bit like a wedding band, it never stops, and everything we have all thought comes (P1). 
which, presented as one circle inside another, assume connectivity. In contrast, more oppositional, didactic spaces assume separation and can lead to the power differentials which often characterise hierarchies.

Despite the initial attractiveness of such a simple dichotomy, the patterns of meaning relating to hierarchical and holarchic collages overlap and are in reality complex. There are often elements of hierarchy exhibited in the holarchic images and vice versa. Supportive structures are a key feature of holarchic images, whilst hierarchies have room for individual expressions of leadership within a clear pattern of roles and responsibilities, evidenced in multiple distributed systems. Thus the multi-faceted nature of leadership is illustrated through this representational approach.

Many of the collages depicted straight lines which could be variously interpreted (Figure 3).

\section{FIGURE 3 HERE}

These lines are particularly interesting where they feature in an otherwise 'holarchic collage'. In some cases, the lines represent a barrier - for example, a barrier to understanding the leadership activities of those 'above you' (left-hand collage, Figure 3), or a barrier to a meaningful connection between students and staff (central collage, Figure 3). However, in other cases participants described how the line acts as a 'holding' image, with a degree of protection offered in this case by the harmonious working of colleagues (right-hand collage, Figure 3). This is an interesting variance and introduces contrasts of meaning which are more likely to emerge through a collage methodology due to its facilitation of an engagement with physical representations.

There is also a potential disconnection here between what might be an initial, logical or assumed interpretation by a researcher of an object within the collage and its actual meaning as identified by the collage-maker. This adds weight to the argument for using the combination of a visual interpretation and participant commentary to inform the understanding of an image which might otherwise have been misinterpreted.

\section{Images of identity}

As evidenced in many of the above images, collage-makers chose some provocative symbols to represent the identity of particular groups or individuals within their school. By identity here we are referring to an imputed defining characteristic of groups or individuals and their role in the school. Many students began their commentary on their collage with an explanation of their representation of the school's headteacher, represented by a number of students as a star and in one case as a crown, showing his position as the king of the school (E1). These symbols are placed at the top of each collage, suggesting the headteacher's position of power, an interesting indication of the early development of the strong leader model which may inhibit the development of shared 
leadership cultures. The spoken commentaries confirm that collage-makers perceived that this power was being used for the good however. One student's representation of the headteacher as a fire-breathing dinosaur is particularly interesting, with the collagecreator choosing this symbol to represent the headteacher as courageous and strong, like a Tyrannosaurus Rex (D5). The image of the headteacher as a strong protector is thus emphasised. In collages produced by staff the image of the headteacher is generally not differentiated from other members of the leadership team, although one teacher represented the headteacher as a star.

A range of symbols and materials were used by participants to represent students. Students were often represented as a mass to demonstrate their dominant numbers in the school. However, their uniqueness was underlined by the choice of a mixture of materials, varying from coloured straws to wooden discs to shiny, sparkly beads and sequins, to represent individual students within this student body. The choice of these materials often appeared to be deliberate and can be evocative of the moral imperative which underlines teaching for the participant. One collage-maker, for example, chose to represent students as wooden discs because they can be shaped (A3). For another, the representation of students by sequins recognises their position as our shining stars (B3).

\section{Images of distributed leadership as a social process}

As has been demonstrated, collage has the potential to surface and convey the complexity of participants' experiences of leadership. We were particularly interested in using collage to learn more about participants' understandings of leadership as a social process. In a review of research into distributed leadership and social justice (Woods and Roberts, 2013), we distinguished between analytical and applied conceptualisations of such leadership. We concluded that a key analytical understanding of distributed leadership is the view that leadership is emergent, arising through complex, interactive processes, rather than being the preserve of those in senior roles with positional leadership authority. This social process view of leadership offers a conceptual lens through which to understand actual leadership practice, an understanding which can be deepened through returning to the collages (Figure 4).

\section{FIGURE 4 HERE}

The maker of the left-hand collage (Figure 4) wished to represent leadership as an attitude, a behaviour, rather than a role or title (C6). Moreover, he wanted to suggest how the practice of leadership could empower all within the school. The flexibility of leadership patterns within the school was seen as a great strength, a way of legitimising activity which improved student learning without such activity having to emanate from someone with a title. Wholly democratic leadership was not a feature of the school, nor was it wished for. Instead, the need for direction from senior leaders was acknowledged, but presented as mediated and interpreted by people across the organisation, who themselves might initiate change as part of their everyday practice. 
The central collage (Figure 4) highlights the place of students in this shared leadership activity, but positions them as passive. For this participant, a member of staff, leadership roles offered to students are tokenistic, hence the representation of students by wooden tokens in his collage. This participant did not see students as having a central role to play in responding to and therefore potentially shaping the leadership strategies of others. Instead, they were seen as passive receivers. The legitimacy and authenticity of the leadership roles offered to students were similarly questioned by the maker of the right-hand collage (Figure 4), a student within the same school.

They just made them up. They are trying to give people roles and stuff but they don't really have any substance (E4).

In the right hand collage (Figure 4), the student imagined leadership within the school as represented by two triangles. The top triangle represents a hierarchy of leaders, whilst the second triangle, partially obscured by the yellow balloon, represents the body of students who do not have overt leadership roles, the majority of students in the school. For this collage-maker, authentic leadership does not come from a title. It seems to us that this student is taking the view that authentic leadership is not title-dependent but arises from the individual purpose and self-directed activity of this majority.

Other collages allow a deepening of an understanding of the social process of leadership (Figure 5).

\section{FIGURE 5 HERE}

The left-hand collage (Figure 5) represents a leadership waterfall, which allows all members of the community to exercise leadership through the development and execution of an idea.

... and at the bottom there is a pool which goes round and round and anyone can take the journey from having an idea about leadership and going through whatever process (C3).

The journey over the leadership waterfall takes place in a balloon and is conceived as a series of interactions with those who could influence the outcome of any leadership initiative. Collaboration with others is particularly important, represented by the two straws in the basket of the balloon. We might see this as reflecting Yukl's (2013) view of leadership as a process of shared influence, but making the collaborative imperative more explicit. 
In the central collage (Figure 5), voice and access are introduced as key concepts in the social process of leadership. The body of students is represented by the coloured straws and beads at the right of the collage, with those students with named leadership roles such as year council members represented by the wooden discs to their left. These students have a mandated right to talk and some access to the school's headteacher, demonstrated by the arrows. Other students, the coloured beads, face many obstacles between themselves and the headteacher, represented as towering over the far left of the collage. Despite this, the collage-maker sees students as holding leadership in a different way, through their position as the backbone of the school (E6) and thus potential change agents.

Interestingly, the maker of the right-hand collage (a teacher) challenges this view of a plethora of organisational actors initiating, influencing and co-creating change. The blue ribbon indicates a structured pattern of improvement, with the plane indicating the speed of change. The dinosaurs are used in an amusing yet effective way to suggest that some are resistant to this change. This does not mean that change does not happen but such resistance may alter its nature.

Key areas of learning about leadership from our analysis of the collages have been illustrated in the discussion in this section. They show diverse images and perspectives on hierarchy, holarchy, identity and social processes of leadership, including metaphors that convey aspects of experiencing leadership important to participants. The degree of confidence in the ability of all to bring about change is variable, yet in no collage was it non-existent. Even the most hierarchical images offered some indication of the ability of those at the bottom to have some small degree of influence. In more holarchic images, opportunities for purposeful innovation are more widely spread. Having explained our approach to collage as a research method and offered some insight into the kind of findings we identified, we turn now to theorising collage as a methodological approach.

\section{Theorising the value of collage in exploring educational leadership}

In the discussion at the beginning of this article we commended the value of arts-based methods, in contrast to a reliance on more traditional methods, as means of facilitating the release of different forms of understanding. In this section we suggest that these different forms of understanding arise in part from the way collage-creation encourages a seeing of the wholeness of a topic. Before discussing wholeness, we suggest how the physicality of collage-creation is integral to its value as a method. The discussion concludes by highlighting the value of participant agency that a use of collage can enable.

\section{Physicality}

The collaging experience offered to participants in the two studies gave them the potential to try things out, to move pieces around and thus to create a new way of expressing either original thoughts or new ways of seeing, stimulated through the making process itself (Gauntlett, 2011). The value of 'mind-wandering' as a catalyst to the development 
of new ideas and understandings (Corballis, 2015) could be seen to be fuelled by the opportunity to experiment with physical materials (Jarvis and Graham, 2015).

The impact of the physicality of the collage methodology is of particular interest to us. Hornecker (2011) highlights the connection between physical movement and the expression of felt emotion. Sennett (2009) suggests that, additionally, physical movements can impact on cognitive understanding. In our collage work, the physicality of moving pieces, of changing the shape and contours of the collages which themselves exist as physical objects in the material world, appeared to facilitate the external expression of feelings which might otherwise have remained within. For example, the creator of the collage on the right in Figure 2 above uses imagery to describe the almost mystical nature of leadership activity. The re-connection of body and mind in such a process of self-understanding (Payne, 2014) can energise the research participant. We highlighted earlier that in human experience there are points where words are inadequate to explain what is known, felt or believed. This linking of collage with a fundamental feature of being human gives collage as a methodology a status which eludes it if seen as simply a childlike activity.

\section{Wholeness}

As described above, the second stage of visual data analysis, that is, working as a team to 'read across' the collages visually, allowed us to be open to the 'wholeness' of each collage, to respond to the 'full picture' of what was being presented to us. Berger (1972) suggests one of the fundamental features of art to be its ability to be read as a whole, to be understood in its entirety, rather than in a piecemeal fashion as a linear set of ideas necessitated by presenting something in written form. Collage allows for a more holistic presentation, and thus a deep understanding of the complexities of the experience of leadership. Our analysis of the data reported above resulted in what we believe to be new insights into the complexities inherent in shared leadership understanding and practice.

\section{Participant agency}

By participant agency we refer to the research participants' ability to act with some degree of independence within the research process, with their actions self-authored rather than wholly determined by others. The level of control which a collage-based methodology gives to the research participants is notable. Participants are not responding to a series of questions and thus a pre-determined area of thinking set by an outsider. Instead they are responding to a wide brief - in this case, how do you see leadership in your school/setting? - in an individual, self-determined way. Participant quotations from the data given above demonstrate the individuality of experience and the confidence with which such distinctiveness is expressed in the explanation of their collage.

\section{Conclusions}


This article contributes to theorising the value of collage as a methodological approach. We have explained the five point process of analysis that we used, namely

- listening to the accounts of the collage given by the collage-maker

- working as a team to 'read across' the collages visually

- grouping the collages according to 'striking elements'

- multi-media analysing of the story of the collage

- identifying areas of learning about the topic of leadership

Gerstenblatt (2013) argues that collage is gaining stature as a research methodology in many disciplines. This article supports this movement. As a contribution to theorising collage as a research process, three key dimensions integral to the practice of collage creation were outlined, based on our reflections of using this method:

- physicality - the value of moving artefacts and materials to create images

- wholeness - the ability of an image to allow a picture of the phenomenon to be seen, as distinct from a linear account

- participant agency - the collage creator being the designer and expert in the meaning of the image.

We have also tried to illustrate the depth of learning about leadership as a social process which this arts-based methodology can offer. Collage's potential to tap into deeply felt experiences of leadership not previously consciously reflected on, understood or narrated is central in this regard. This facilitates both commonalities and differences of view to be expressed amongst participants, with differences sometimes being complementary and sometimes contradictory or indicating possible areas of disagreement or conflict.

Leadership, like collage, is an activity which involves creativity, initiative and action, an activity not necessarily undertaken by one individual but shaped and influenced by many. In offering collage as an alternative or supplement to common methodological approaches to leadership research, this article has both enriched the empirical foundation of the arts-based methodological literature whilst also throwing new light on how leadership is experienced in educational settings. We intend to continue to mine collage's potential to offer an equal voice to all research participants and to reveal new connections and hence understandings of leadership as a social process.

\section{References}

Bagley, C. and Castro-Salazar, R. (2012) Critical arts-based research in education: performing undocumented historias, British Educational Research Journal, 38 (2), 239260. 
Bell, J. (2002) Narrative inquiry: more than just telling stories. TESOL Quarterly, 36(2), 207-213.

Berger, J. (1972) Ways of seeing. British Broadcasting Corporation and Penguin.

Black, A. (2002) Making sense of what it means to teach: artful representations as meaning-making tools. Teacher Development, 6(1), 75-88.

Boren, M. T. \& Ramsey, J. (2000) Thinking Aloud: Reconciling Theory and Practice. IEEE Transactions on Professional Communication, 43(3), 261-278.

Branch, J. L. (2001) Junior high students and Think Alouds. Generating informationseeking process data using concurrent verbal protocols. Library \& Information Science Research, 23, 107-122.

Bresler, L. (2006) Toward connectedness: Aesthetically based research. Studies in Art Education,48, 52-69.

Butler-Kisber, L. (2008). Collage as inquiry. In J. G. Knowles \& A. L. Cole (Eds.), Handbook of the arts in qualitative research, 265-276. Thousand Oaks, CA: Sage.

Butler-Kisber, L. and Poldma, T. (2010) The Power of Visual Approaches in Qualitative Inquiry: The Use of Collage Making and Concept Mapping in Experiential Research. Journal of Research Practice, 6(2). Available at: http://jrp.icaap.org/index.php/jrp/ article/view/197/196

Accessed: 5.12 .16

Clandinin, D., Murphy, M., Huber, J. \& Orr, A. (2009) Negotiating Narrative Inquiries: Living in a Tension-Filled Midst. The Journal of Educational Research, 103(2), 81-90.

Corballis, M. (2015) The wandering mind: What the brain does when you're not looking. Chicago: University of Chicago Press.

Diaz, G. (2002). Artistic inquiry: On Lighthouse Hill. In C. Bagley \& M. B. Cancienne (Eds.), Dancing the data (pp. 147-161). New York, NY: Peter Lang.

Downes, P. (2013) Developing a framework and agenda for students' voices in the school system across Europe: from diametric to concentric relational spaces for early school leaving prevention. European Journal of Education, 48(3), 346-362.

Eisner, E. (1993) Forms of Understanding and the Future of Educational Research. Educational Researcher, 22(7), 5-11.

Eisner, E. (2004) What can education learn from the arts about the practice of education? International Journal of Education and the Arts, 5(4), 1-13. 
Frost, D. (2013) Teacher-led development work: a methodology for building professional knowledge, HertsCam Occasional Papers April 2013, HertsCam Publications, Available at: www.hertscam.org.uk Accessed: 6.6.16.

Gale, K. \& Wyatt, J. (2006) Inquiring Into Writing: An Interactive Interview. Qualitative Inquiry, 12(6), 1117.

Gauntlett, D. (2011) Making is Connecting. Cambridge: Polity Press.

Gerstenblatt, P. (2013) Collage portraits as a method of analysis in qualitative research, International Journal of Qualitative Methods, 12, 295-309.

Gourlay, L. (2009) Threshold practices: becoming a student through academic literacies. London Review of Education, 7(2), 181-192.

Holgraves, T. (2004) Social desirability and self-reports: testing models of socially desirable responding. Personality and Social Psychology Bulletin, 30, 161-172.

Hornecker, E. (2011) The role of physicality in tangible and embodied interactions. Interactions, March and April.

Jarvis, J. and Graham, S. (2015) Innovative pedagogies series: 'It's all about the shoes'. Exploring the perspectives of others and ourselves in Teacher Education. Higher Education Academy. London: Higher Education Academy.

James, A. and Brookfield. S. (2014) Engaging imagination: Helping students to become creative and reflective thinkers. San Fransisco: Jossey Bass.

Kaminska, O. and Foulsham, T. (2013) Understanding sources of social desirability bias in different modes: evidence from eye-tracking. ISER Working Paper series, March 2013. Available at: https://www.iser.essex.ac.uk/research/publications/working-papers/iser/ 2013-04.pdf (Accessed: 13.4.18)

Leitch, R. (2006) Limitations of language: developing arts-based creative narrative in stories of teachers' identities. Teachers and Teaching: Theory and Practice, 12(5), 549-569.

Loads, D. (2009) Putting ourselves in the picture: art workshops in the professional development of university lecturers. International Journal for Academic Development, 14(1), 59-67.

Luttrell, W. (2010) 'A camera is a big responsibility': a lens for analysing children's visual voices. Visual Studies, 25(3), 225-237

MacBeath, J. (2002) The Self-Evaluation File: good ideas and practical tools for teachers, pupils and school leaders. Glasgow: Learning Files Scotland. 
Payne, H. (2014) Our body and mind are one. LINK, School of Education journal, University of Hertfordshire, 1(1) Available at: http://www.herts.ac.uk/link/volume-1-issue-1/our-body-and-mind-are-one (Accessed: 1.1.18)

Prosser, J. (ed) (1998) Image-based Research, London: RoutledgeFalmer.

Roberts, A. (2016) An exploration of the relationship between academics' conceptions of their professional identity and their attitudes and approaches to academic writing in a School of Education in a post-1992 university. Unpublished thesis. London: King's College, London.

Sennett, R. (2009) The craftsman. London: Penguin.

Simons, H. (2009) Case study research in practice, London: SAGE.

Spouse, J. (2000) Talking pictures: investigating personal knowledge through illuminative art work. Nursing Times Research, 5(4), 253-261.

Stacey, R. (2012) Tools and Techniques of Leadership and Management: Meeting the Challenge of Complexity. London: Routledge.

Sternberg, R.J. and Horvath, J.A. (eds.) (2009) Tacit knowledge in professional practice. Researcher and practitioner perspectives. London: Taylor and Francis.

Thaiss, C. \& Zawacki, T. (2006) Engaged Writers and Dynamic Disciplines. Research on the Academic Writing Life. Portsmouth: Boynton/Cook.

Van Manen, M. (1990) Researching Lived Experience. Human Science for an Action Sensitive Pedagogy. New York: State University of New York.

Weber, S. \& Mitchell, C. (1996) Drawing ourselves into teaching: studying the images that shape and distort teacher education. Teaching and Teacher Education, 12(3), 303-313.

Woods, P. A. (2016) 'Authority, Power and Distributed Leadership', Management in Education, 30(4): 155-160.

Woods, P. A. (in press 2018) School Organisation: Authority, status and love as an integrative power', in M. Connolly, D. H. Eddy Spicer, C. James \& S. Kruse (eds), The International Handbook on School Organization, London: SAGE.

Woods, P. A. and Roberts, A. (2018) Collaborative School Leadership: A critical guide. London: SAGE 
Woods, P. A. and Roberts, A. (2013) 'Distributed Leadership and Social Justice: A case study investigation of distributed leadership and the extent to which it promotes social justice and democratic practices', European Policy Network on School Leadership (EPNoSL). Available at http://www.schoolleadership.eu/sites/default/files/uk final report distributed-leadership-and-social-justice 0.pdf (Also published, without the detailed appendices, in L. Moos and P. Hatzopolous (eds), School Leadership as a driving force for equity and learning: Comparative perspective, EPNoSL. Available at http:// www.schoolleadership.eu/sites/default/files/epnosl-d4.1.pdf )

Woods, P.A., Roberts, A. and Chivers, L. (2016) Collaborative Teacher Learning: Cases from the HertsCam Network. Hatfield, Hertfordshire: Centre for Educational Leadership, School of Education, University of Hertfordshire.

Yukl, G. (2013) Leadership in organizations. Harlow: Pearson Higher Education Ltd. 


\section{Figures}

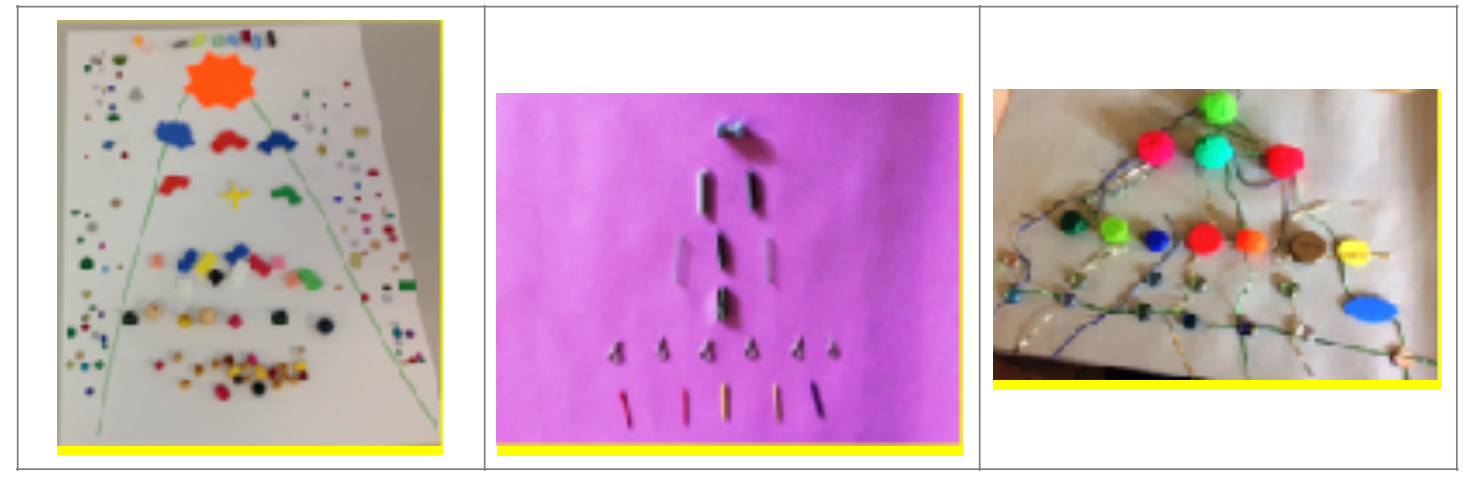

Figure 1: Images of hierarchy

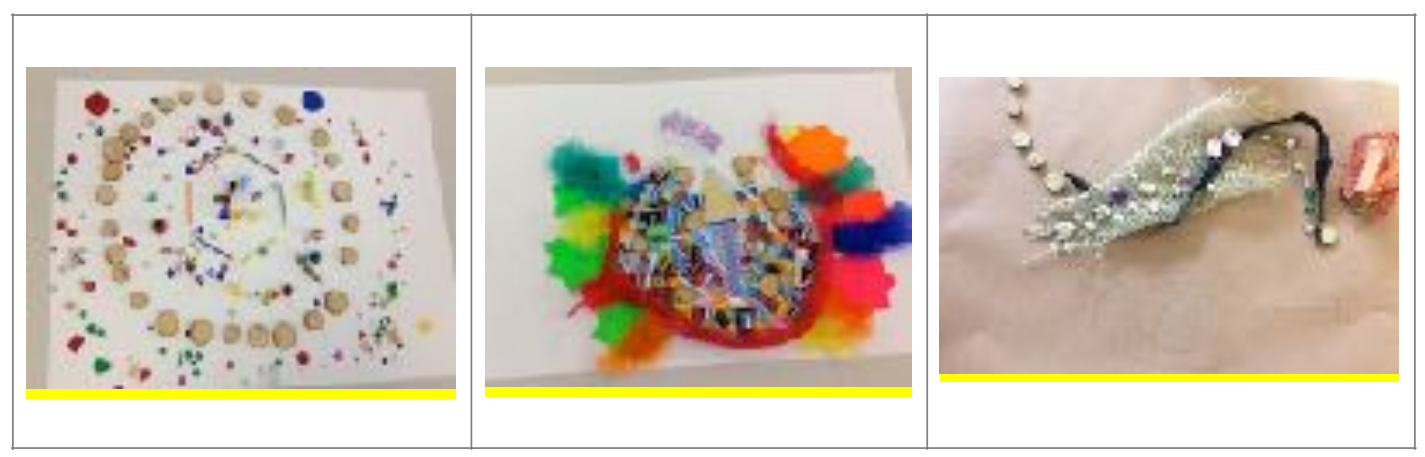

Figure 2: Images of holarchy

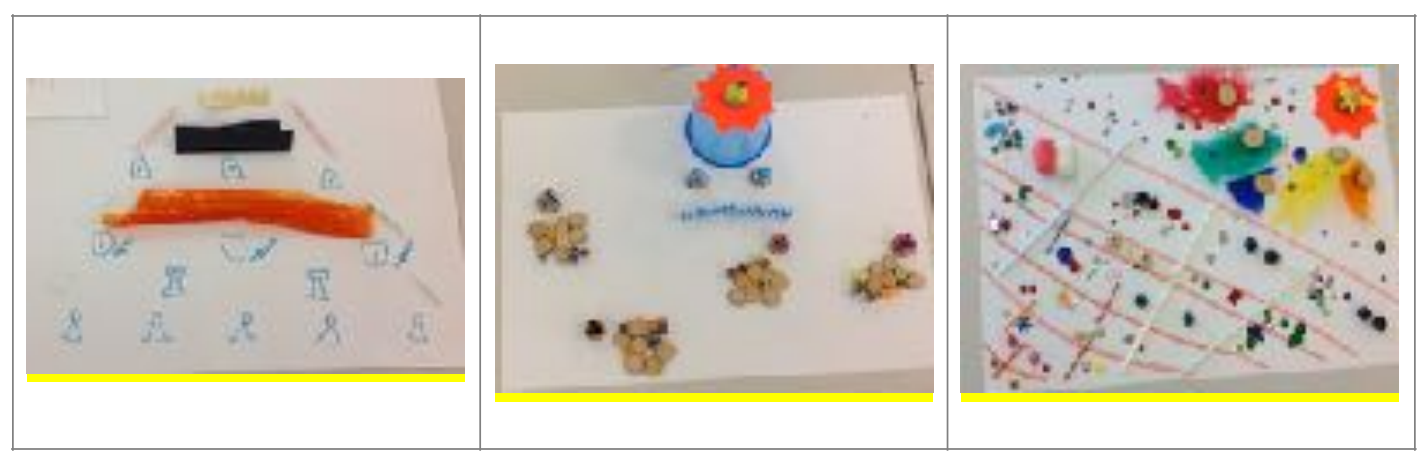

Figure 3: Barriers and 'holding' images 


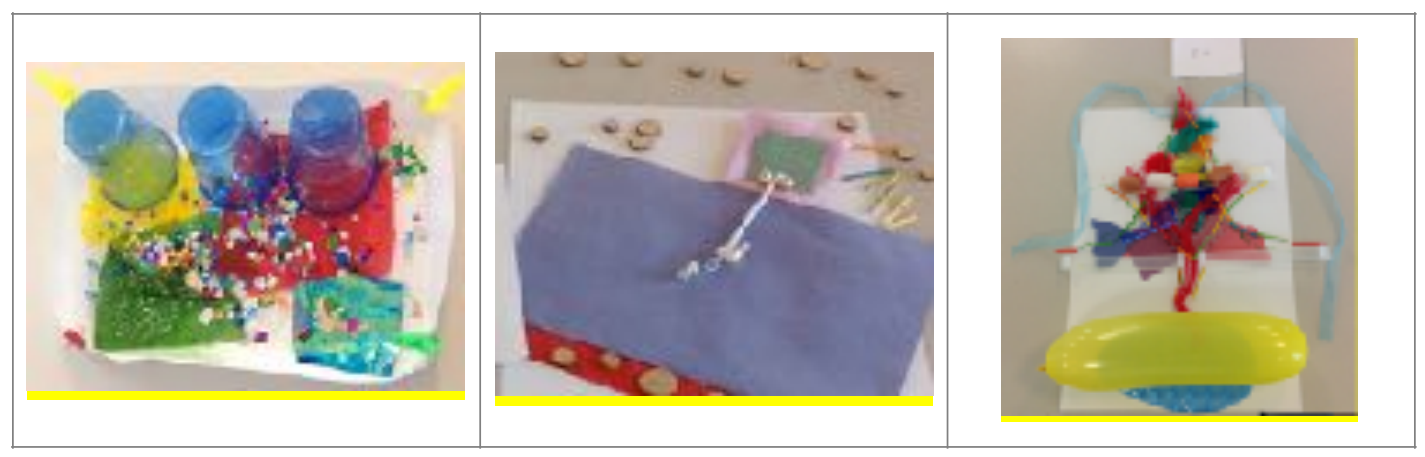

Figure 4: Leadership as a social process (1)

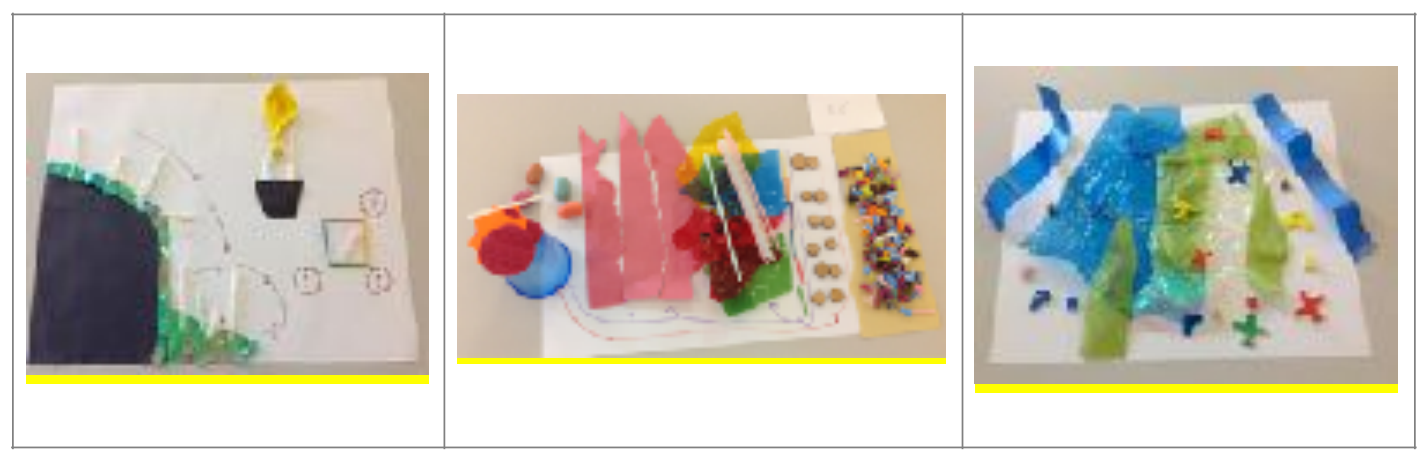

Figure 5: Leadership as a social process (2) 